\title{
Bovine subclinical mastitis caused by different types of coagulase-negative staphylococci
}

\author{
B.-M. Thorberg, ${ }^{*}$ M.-L. Danielsson-Tham, $\dagger$ U. Emanuelson, $\ddagger$ and K. Persson Waller $¥ \S^{1}$ \\ *Swedish University of Agricultural Sciences, Department of Biomedical Sciences and Veterinary Public Health, SE-75007 Uppsala, Sweden \\ †Örebro University, Department of Restaurant and Culinary Arts, SE-71260 Grythyttan, Sweden \\ $\ddagger$ Swedish University of Agricultural Sciences, Department of Clinical Sciences, SE-75007 Uppsala, Sweden \\ $\S N a t i o n a l$ Veterinary Institute, Department of Animal Health and Antimicrobial Strategies, SE-75189 Uppsala, Sweden
}

\begin{abstract}
Subclinical mastitis caused by intramammary infections (IMI) with coagulase-negative staphylococci (CNS) is common in dairy cows and may cause herd problems. Control of CNS mastitis is complicated by the fact that CNS contain a large number of different species. The aim of the study was to investigate the epidemiology of different CNS species in dairy herds with problems caused by subclinical CNS mastitis. In 11 herds, udder quarter samples were taken twice 1 mo apart, and CNS isolates were identified to the species level by biochemical methods. The ability of different CNS species to induce a persistent infection, and their associations with milk production, cow milk somatic cell count, lactation number, and month of lactation in cows with subclinical mastitis were studied. Persistent IMI were common in quarters infected with Staphylococcus chromogenes, Staphylococcus epidermidis, and Staphylococcus simulans. The results did not indicate differences between these CNS species in their association with daily milk production, cow milk somatic cell count, and month of lactation in cows with subclinical mastitis. In cows with subclinical mastitis, S. epidermidis IMI were mainly found in multiparous cows, whereas $S$. chromogenes IMI were mainly found in primiparous cows.
\end{abstract}

Key words: dairy cow, subclinical mastitis, coagulasenegative staphylococci, epidemiology

\section{INTRODUCTION}

Clinical and subclinical mastitis caused by IMI with CNS is common in many intensive dairy production systems around the world. According to a meta-analysis from 2002 (Djabri et al., 2002), the prevalence of IMI caused by CNS may vary between 5.5 and $27.1 \%$ at the udder quarter level. The overall prevalence of subclinical mastitis in Sweden is not known, but the propor-

Received March 5, 2009.

Accepted July 1, 2009.

${ }^{1}$ Corresponding author: Karin.Persson-Waller@sva.se tion of cases with CNS among bacteriologically positive cases with subclinical mastitis is estimated to be approximately 25\% (Swedish Dairy Association, 2007). In some herds, CNS infections cause herd problems with high bulk milk SCC (BMSCC), a high incidence of clinical cases, or both (Harmon and Langlois, 1989; Davidson et al., 1992). However, limited information is available on how CNS problems develop in a herd and how the infection spreads and persists. Consequently, it is difficult to give advice on mastitis control in these herds.

Studies on CNS mastitis are complicated by the fact that CNS most commonly are referred to as 1 group of bacteria, but in reality consist of many different species. In studies on bovine mastitis, 9 to $16 \mathrm{CNS}$ species or subspecies have been diagnosed (Harmon and Langlois, 1989; Jarp, 1991; Birgersson et al., 1992; Aarestrup and Jensen, 1997). The most common species found are Staphylococcus chromogenes, Staphylococcus simulans, Staphylococcus xylosus, Staphylococcus epidermidis, Staphylococcus hyicus, and Staphylococcus hemolyticus. Most commonly, differentiation between CNS species is based on morphology and biochemical properties (Devriese et al., 1985; Kloos and Jorgensen, 1985). Such methods could, however, be difficult to perform, which could lead to the use of readily available commercial identification kits, but also to differences between laboratories if the methods used have not been validated for the bacterial population of interest or are low performing. In the future, genotyping tools may be a solution, but no widely accepted gold standard for species identification of CNS by genotypic traits is available at present.

Conflicting results have been presented concerning the association between CNS IMI and milk production. Early studies described no correlation (Eberhart et al., 1982) or a negative correlation (Timms and Schultz, 1987) between such infections and milk production. Later studies found higher milk production in cows with CNS IMI than in healthy cows in 2 large US surveys (Wilson et al., 1997; Schukken et al., 2009). In a study on associations between milk production and 
clinical mastitis, multiparous cows affected by clinical CNS mastitis had higher milk production before the onset of mastitis than did healthy cows (Gröhn et al., 2004). One reason for the variable results may be a failure to acknowledge variation between CNS species. However, no studies have investigated possible differences between different CNS species on the associations with SCC or milk production.

In general, very limited data are available on differences in the epidemiology of different CNS species, such as in the persistency of IMI. In one study of a university herd, S. chromogenes IMI were considered as being more persistent than IMI with other CNS species during lactation (Harmon and Langlois, 1989). In contrast, Aarestrup et al. (1995) reported that the prevalence of $S$. chromogenes declined very rapidly 1 mo after calving among dairy heifers from different herds and that $S$. simulans was involved in persistent IMI. Overall, the spontaneous elimination rate of CNS in the udder has been reported to be both higher and lower compared with other udder pathogens (Rainard and Poutrel, 1982; Timms and Schultz, 1987; Davidson et al., 1992).

Little is also known regarding the importance of cow factors, such as lactation stage and lactation number, on the occurrence of CNS IMI. Some reports state that the early-lactation cow is more susceptible to CNS IMI than cows in later stages of lactation (Harmon and Langlois, 1989), whereas other studies state that most CNS IMI occur at the end of the lactation period (Davidson et al., 1992). According to Oliver and Jayarao (1997), there is a trend for the peak prevalence of CNS to occur during the prepartum period, for many CNS IMI to be eliminated around calving, and for the prevalence to decline during lactation. Moreover, CNS IMI has been reported to be more prevalent in primiparous cows than in multiparous cows (Matthews et al., 1992; Oliver and Jayarao, 1997).

The major aim of the present study was to investigate the epidemiology of different CNS species in dairy herds with problems caused by subclinical CNS mastitis. The hypotheses were that CNS species would differ in their ability to induce persistent IMI, and that CNS species would differ in their association with milk production and SCC. Associations between CNS species, and lactation number and month of lactation were also investigated.

\section{MATERIALS AND METHODS}

\section{Herds}

Eleven dairy herds in southern and middle Sweden were included in the study. Herds considered by field veterinarians to have a herd mastitis problem caused by CNS infections (based on the incidence of subclinical CNS mastitis, clinical CNS mastitis, or both and on BMSCC) were selected. The farms were also representative of Swedish dairy herds regarding cow number, milk production, and management routines (housing, feeding, and milking) and did not have any obvious management problems. Another selection criterion was that information on monthly SCC, lactation number, calving date, monthly milk yield, reproduction data, and veterinary-treated diseases was available for all cows on the farm. In Sweden, all veterinary-treated diseases must be reported to the Swedish animal disease recording system, and are also registered in the Swedish official milk recording system (SOMRS; Olsson et al., 2001) run by the Swedish Dairy Association. Nine of the herds included in this study were enrolled in the SOMRS, whereas 2 herds had their own data-recording systems. In the year of the study, the mean (range) herd size of the study herds was 65 (22 to 112) cows, the average annual milk production was $8,205(6,547$ to 9,200$) \mathrm{kg} / \mathrm{cow}$, and the geometric mean of the herd BMSCC was $257,000(134,000$ to 394,000$)$ cells/mL. In the year of the study, $85 \%$ of all Swedish dairy cows were enrolled in the SOMRS, the mean herd size was 32.2 cows/herd, the average annual milk production was $7,400 \mathrm{~kg} / \mathrm{cow}$, and the geometric mean of the herd BMSCC was 213,000 cells/mL. In study herds, the median (range) proportion of first-parity cows was $40.2 \%$ (18.8 to $54.2 \%)$.

Ten of the farms housed their cows in tie stalls with straw as bedding, whereas 1 farm had a free-stall barn. Milking was performed twice per day on all farms. All herds used teat dipping with iodine after milking and selective dry cow therapy based on udder health status. The cows were of the major Swedish dairy breeds Swedish Red and Swedish Holstein, or were cross-bred between those 2 breeds.

\section{Milk Sampling and Analyses}

The principal investigator, or trained technicians, visited each herd twice with a 4 -wk interval. The visits were performed as close as possible [on average within $3 \mathrm{~d}$ (range 1 to $7 \mathrm{~d}$ )] after the monthly milk recordings of cow SCC and milk yield. At each visit, quarter milk samples were taken aseptically from all lactating cows directly after milking. The samples were transported chilled to the laboratory, and the California Mastitis Test (CMT; scored 1 to 5 corresponding to no reaction, trace, mild reaction, moderate reaction, and strong reaction, respectively) and bacteriological analyses were initiated within $24 \mathrm{~h}$ after sampling. Ten microliters of milk was inoculated on agar plates supplemented with 
$5 \%$ bovine blood, which were incubated at $37^{\circ} \mathrm{C}$ for 18 plus $24 \mathrm{~h}$. All isolates identified as CNS based on colony morphology, gram staining (positive), catalase reaction (positive), and coagulase test (positive), and with growth of at least $5 \mathrm{cfu}$ in pure culture in samples taken on the first sampling occasion were subjected to CNS species identification by using all the conventional biochemical methods described by Thorberg and Brändström (2000). For novobiocin-sensitive CNS isolates identified in samples taken at the second sampling, a simplified identification system, novobiocin-sensitive CNS built on biochemical tests, was used (Thorberg and Brändström, 2000). All other CNS isolates identified in samples from the second sampling time were identified by the same biochemical methods used for samples taken at the first sampling. All other bacteriological agents were identified based on the Nordic recommendation for mastitis diagnoses (Klastrup and Schmidt Madsen, 1974).

\section{Statistics and Definitions}

Udder Quarter Level. The overall udder quarter prevalence of bacteriological findings, and the distribution of different CNS species among CNS-positive samples were calculated in each herd at each sampling occasion. The proportion of persistent udder quarter infections was calculated for each CNS species. A persistent CNS infection was defined as udder quarter isolation of the same CNS species in milk samples taken at both sampling occasions. A CNS infection was considered not persistent when it was identified only at the first sampling. Udder quarters with a persistent CNS infection were further categorized based on the presence (CMT 3 to 5) or absence (CMT 1 to 2) of an inflammatory reaction.

Cow Level. For the evaluation of differences between CNS species regarding associations with daily milk production and composite SCC (CSCC), cows with subclinical CNS mastitis caused by the 3 most common CNS species, namely, S. chromogenes, S. epidermidis, and $S$. simulans (together representing $>90 \%$ of all persistent CNS diagnoses), were selected. Cows were defined as having persistent subclinical CNS mastitis if a CMT score of 3 to 5 was found on at least 1 sampling occasion and the same CNS species was isolated on both sampling occasions. Cows were defined as having nonpersistent subclinical CNS mastitis if a CMT score of 3 to 5 was found on at least 1 sampling occasion but if CNS was isolated only at the first sampling. If a cow had udder quarters infected with different CNS species, the cow was defined as having the infection with the highest CMT score. In addition, cows defined as having subclinical mastitis had to have a CSCC of $>100,000$ cells $/ \mathrm{mL}$ at both monthly milk recordings during the sampling period. Healthy control cows were defined as having no bacterial growth, a CMT score of 1 to 2 in all udder quarters, and a CSCC of $<100,000$ cells/mL at both monthly milk recordings.

In the statistical analyses, the average milk yield and CSCC from the 2 monthly milk recordings occurring during the sampling period were used. The CSCC was log-transformed (InCSCC) before statistical evaluations were made. The associations between cow status (healthy, nonpersistent subclinical CNS mastitis, or persistent subclinical CNS mastitis) and $\operatorname{lnCSCC}$ and daily milk production were studied by using general linear mixed models. The statistical models included, in addition to the effect of cow status, the fixed effects of lactation number $(1,2, \geq 3)$, month of lactation $(0$, $+1,2,3,4,5,6,7,8,9, \geq 10)$, their interaction, and the random effect of herd. The effects of month of lactation, and the interaction between lactation number and month were not significant in the model of $\operatorname{lnCSCC}$ and were thus excluded from the model.

Differences in lactation number between the 3 CNS species specified above were tested using the chi-squared test. All cows with subclinical mastitis, as defined above, were included in the analyses.

\section{RESULTS}

\section{Bacteriological Findings on the Udder Quarter Level}

In Tables 1 and 2 bacteriological findings on the udder quarter level at the 2 sampling occasions are listed for each herd and in total. The total numbers of udder quarter samples were 2,303 (587 cows) and 2,259 (578 cows) at sampling 1 and sampling 2, respectively. The total number of CNS isolates was 277 at sampling 1 and 251 at sampling 2, corresponding to a total udder quarter CNS prevalence of 12.0 and $11.1 \%$, respectively. In total, 11 CNS species were identified. Overall, the most common findings were $S$. epidermidis, S. simulans, S. chromogenes, S. xylosus, and S. hemolyticus. Eight of the CNS species, S. chromogenes, S. epidermidis, S. hemolyticus, S. hyicus, Staphylococcus kloosi, S. simulans, Staphylococcus warneri, and S. xylosus, were isolated in udder quarters both with (CMT 3 to 5) and without (CMT 1 to 2) an inflammatory response (data not shown). Staphylococcus cohnii, Staphylococcus saprophyticus, and Staphylococcus sciuri were isolated only in udder quarters without an inflammatory response.

The herd prevalence of CNS among udder quarter samples varied between 7.2 and $17.5 \%$ and between 5.0 and $18.0 \%$ at sampling 1 and sampling 2 , respectively. Among the herds, the most widespread CNS species were S. chromogenes, S. epidermidis, and S. simulans, 
Table 1. Udder quarter prevalence of bacteriological findings in milk samples taken from all udder quarters of lactating cows in 11 dairy herds at the first of 2 samplings performed 1 mo apart

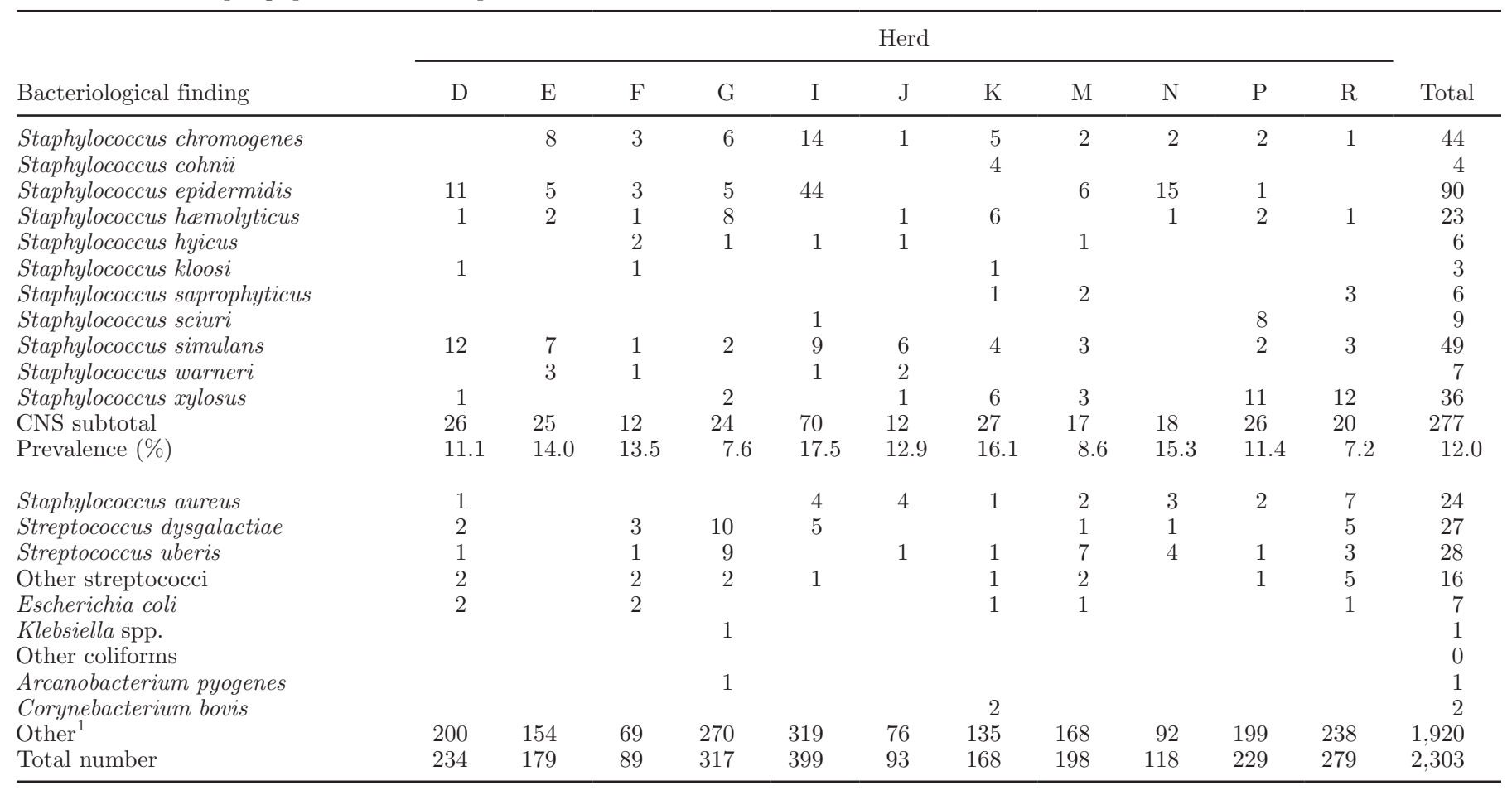

${ }^{1}$ No growth or contaminated sample.

Table 2. Udder quarter prevalence of bacteriological findings in milk samples taken from all udder quarters of lactating cows in 11 dairy herds at the second of 2 samplings performed 1 mo apart

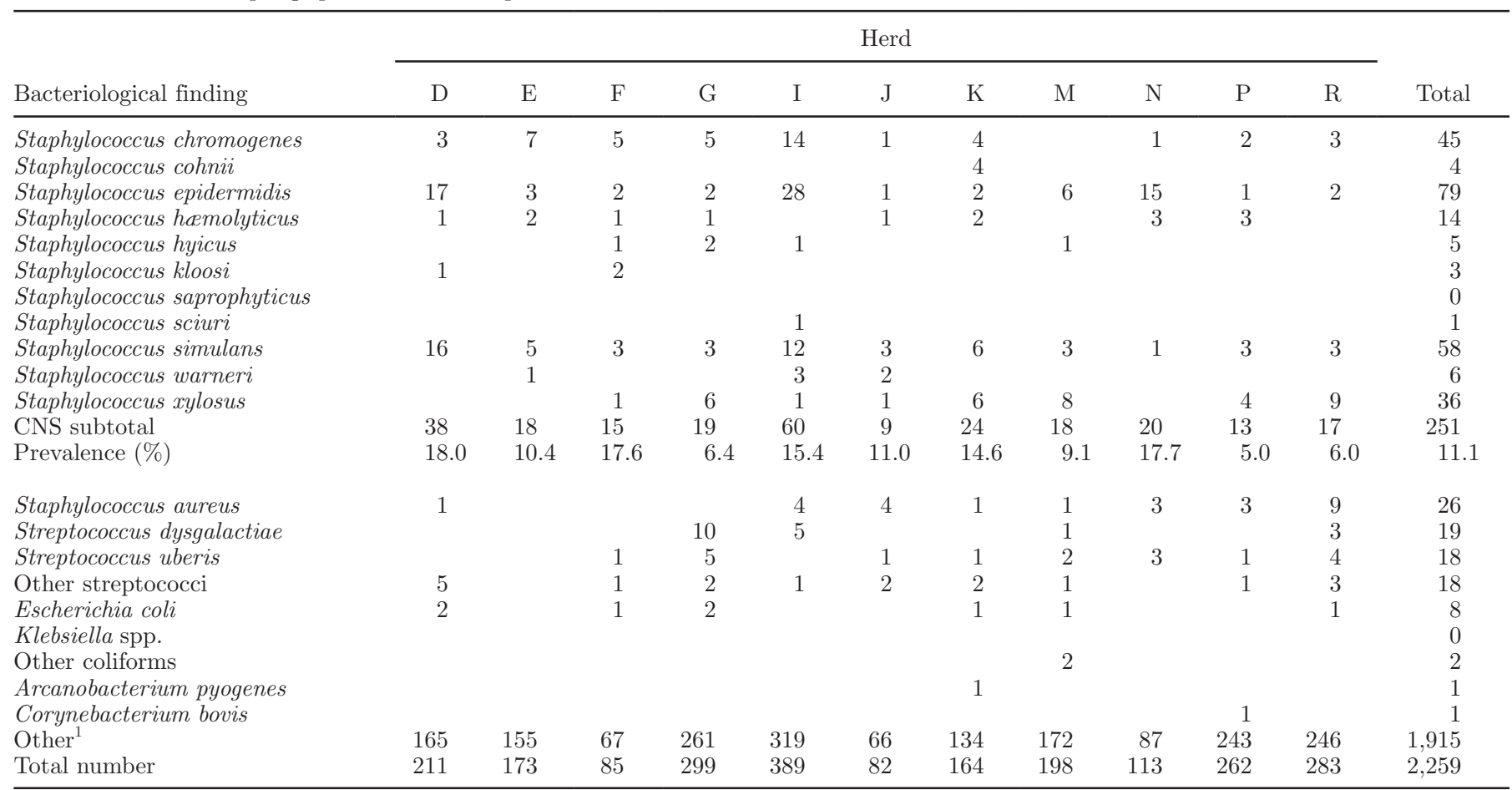

${ }^{1}$ No growth or contaminated sample. 
Table 3. Number of udder quarters with findings of CNS in milk samples taken from lactating cows in 11 herds at the first sampling occasion, total number (\%) of udder quarters with the same finding (persistent infection) at a second sampling 1 mo later, and milk California Mastitis Test (CMT) reaction in persistently infected udder quarters

\begin{tabular}{|c|c|c|c|c|c|}
\hline CNS & Isolated in herd & $\begin{array}{l}\text { Quarters infected } \\
\text { with CNS at the } \\
\text { first sampling }\end{array}$ & \multicolumn{3}{|c|}{ Quarters infected with CNS at both samplings ${ }^{1}$} \\
\hline Staphylococcus epidermidis & D E F G I K M N P R & 90 & 4 & 48 & $52(58)$ \\
\hline Staphylococcus chromogenes & D E F G I J K M N P R & 44 & 1 & 28 & $29(66)$ \\
\hline Staphylococcus xylosus & D E F J K M P R & 36 & 2 & 2 & $4(11)$ \\
\hline Staphylococcus hemolyticus & D E G K P R & 23 & 2 & 3 & $5(22)$ \\
\hline Staphylococcus saprophyticus & $\mathrm{K}$ & 6 & - & - & - \\
\hline Staphylococcus hyicus & G M I F M & 6 & 1 & 2 & $3(50)$ \\
\hline Staphylococcus cohnii & $\mathrm{K}$ & 4 & 2 & - & $2(50)$ \\
\hline Staphylococcus kloosi ${ }^{2}$ & F K R & 3 & - & 1 & $1(33)$ \\
\hline Total & & 271 & 13 & 117 & $130(48)$ \\
\hline
\end{tabular}

${ }^{1} \mathrm{CMT} 1$ to $2=$ no inflammatory reaction; CMT 3 to $5=$ inflammatory reaction.

${ }^{2}$ Doubtful identification.

which were isolated at least once in all herds, whereas S. xylosus and S. hemolyticus were found in 9 herds. In contrast, S. saprophyticus was isolated only in 3 herds, $S$. sciuri in 2 herds, and $S$. cohnii in 1 herd. For the most part, 1 or 2 of the CNS species $S$. chromogenes, $S$. epidermidis, S. hemolyticus, S. simulans, and S. xylosus dominated in a herd.

In all herds, except herds $\mathrm{G}$ and $\mathrm{R}$, CNS were the most prevalent agents found in udder quarters with an inflammatory reaction (data not shown). Streptococcus spp. dominated in herd G, whereas Staphylococcus aureus and Streptococcus spp. were the most common findings in herd R.

\section{Persistence of CNS Infections on the Udder Quarter Level}

Persistence of CNS infections (i.e., finding the same CNS species in the same udder quarter at both samplings) is given in Table 3 for each CNS species. Persistent infections were common (58 to $76 \%$ of the infections) for $S$. chromogenes, S. epidermidis, and $S$. simulans but were infrequent (11 to $22 \%$ ) for $S$. xylosus and $S$. hemolyticus. Most quarters persistently infected with S. chromogenes, S. epidermidis, or S. simulans had an inflammatory reaction, as measured by the CMT (Table 3). Approximately $95 \%$ of the novobiocin-resistant CNS species S. cohnii, S. kloosi, S. saprophyticus, S. sciuri, and S. xylosus were isolated in quarters with a low CMT score (data not shown) and only a few were isolated in cases of persistent infection. Altogether, these novobiocin-resistant CNS species were isolated in 58 udder quarters on the first sampling occasion (Table 3 ), and only $3(5 \%)$ of the udder quarters had persistent infections with an inflammatory reaction.

\section{Associations Between CNS Species, and Daily Milk Production and CSCC}

In total, 587 and 578 cows were sampled on the first and second sampling occasion, respectively. The number of cows sampled twice that had complete milk records was 544. Of those, 380 belonged to cows categorized as healthy, or with subclinical mastitis caused by $S$. chromogenes, S. epidermidis, and S. simulans.

In Table 4, daily milk production and CSCC are given for different categories of cows. Cows with nonpersistent $S$. simulans IMI had significantly lower milk production than healthy cows or cows with persistent $S$. chromogenes, $S$. epidermidis, or $S$. simulans IMI. Cows with nonpersistent subclinical mastitis caused by $S$. epidermidis had significantly lower production than cows with persistent $S$. chromogenes or $S$. simulans mastitis. When comparing all cows with nonpersistent or persistent subclinical mastitis, significantly $(P$ $<0.01$ ) higher milk production was observed among persistently infected cows. Cows with nonpersistent subclinical mastitis had significantly $(P<0.01)$ lower production than healthy cows. Composite SCC did not differ between cows with nonpersistent and persistent subclinical mastitis.

\section{Associations Between CNS Species, and Lactation Number and Month of Lactation}

As shown in Table 5, the distribution between lactation numbers differed between CNS species. Staphylococcus epidermidis was more common in older cows with subclinical mastitis than in first-lactation cows with subclinical mastitis $(P<0.001)$, whereas the opposite was the case for $S$. chromogenes. Staphylococcus 
Table 4. Least squares means (95\% confidence intervals in parentheses) of daily milk production and composite SCC (CSCC) for cows classified as healthy or as having subclinical mastitis caused by a nonpersistent (NP) or persistent (P) infection with Staphylococcus chromogenes (Sc), Staphylococcus epidermidis (Se), or Staphylococcus simulans $(\mathrm{Ss})$

\begin{tabular}{llrcc}
\hline Category & Infection type & $\mathrm{N}$ & Milk production $^{1}(\mathrm{~kg})$ & $\mathrm{CSCC}^{2,3}\left(\times 10^{3} / \mathrm{mL}\right)$ \\
\hline Healthy & & 252 & $27.5(25.8 ; 29.2)$ & $64(52 ; 79)$ \\
Sc & NP & 6 & $24.8(19.8 ; 29.9)$ & $191(105 ; 347)$ \\
& $\mathrm{P}$ & 27 & $28.6(26.0 ; 31.3)$ & $198(143 ; 274)$ \\
Se & NP & 14 & $25.0(21.6 ; 28.3)$ & $184(122 ; 278)$ \\
& $\mathrm{P}$ & 39 & $26.0(23.6 ; 28.5)$ & $217(162 ; 292)$ \\
Ss & NP & 11 & $22.1(18.4 ; 25.8)$ & $192(122 ; 302)$ \\
& $\mathrm{P}$ & 31 & $28.7(26.1 ; 31.3)$ & $256(187 ; 350)$ \\
\hline
\end{tabular}

${ }^{1}$ Significant $(P<0.05)$ differences were found between SsNP, and healthy, SeP, ScP, and SsP, and between $\mathrm{SeNP}, \mathrm{ScP}$, and SsP.

${ }^{2}$ Estimates on a ln-scale back transformed to the observed scale.

${ }^{3}$ Significant $(P<0.05)$ differences were found between healthy and each of the other categories.

simulans was equally distributed between young and older cows with subclinical mastitis.

Differences in month of lactation were not observed among the 3 CNS species. The mean month of lactation was 6.6 for all cows and was 6.8, 7.0, and 7.0 for cows with subclinical mastitis caused by $S$. chromogenes, $S$. epidermidis, and $S$. simulans, respectively.

\section{DISCUSSION}

The most commonly isolated CNS species in the study herds were $S$. epidermidis, S. simulans, S. chromogenes, S. hemolyticus, and S. xylosus. This is in line with findings in early-lactation heifers in a Danish study (Aarestrup and Jensen, 1997) using similar bacteriological diagnostics. In Canadian herds with a high prevalence of CNS, however, Staphylococcus hominis, S. sciuri, and $S$. xylosus were the most prevalent species, followed by S. epidermidis and S. warneri (Davidson et al., 1992). In the present study, S. chromogenes, S. epidermidis, and $S$. simulans were the most widespread among the herds, and these species were often the dominating bacteriological finding in a herd.

Even though the persistency of CNS IMI was evaluated based on a relatively short period of 1 mo, some interesting trends were found. The majority of IMI caused by $S$. chromogenes, S. epidermidis, and S. simulans were persistent, whereas the opposite was the case for $S$. hemolyticus and S. xylosus. Staphylococcus chromogenes has been found to cause persistent infections in previous studies (Todhunter et al., 1993; Taponen et al., 2007), but according to Aarestrup and Jensen (1997), the prevalence of $S$. chromogenes declined rapidly in heifers after calving. In the latter study, the study material was quite different from that of the present study. Few studies have been published on the persistence of $S$. simulans IMI, but in line with our findings, a high proportion of persistent $S$. simulans IMI were reported by Aarestrup et al. (1999) and Taponen et al. (2006). To our knowledge, information on the persistency of $S$. epidermidis IMI has not been reported. In our study, nearly $60 \%$ of such infections were persistent. However, the prevalence of persistent $S$. epidermidis IMI varied markedly between herds (data not shown). In some herds, most IMI were transient, but in 1 herd, $100 \%$ of $S$. epidermidis IMI were persistent. In the latter herd, S. epidermidis was the most dominating udder pathogen. This may also indicate variation in virulence among S. epidermidis strains and that this CNS species may cause long-lasting udder health problems in some herds. Staphylococcus hemolyticus and S. xylosus were also found rather frequently in the present study, but fewer than $20 \%$ of those IMI were persistent, which is in line with the reports of Matthews et al. (1991) and Taponen et al. (2007).

The reasons that some CNS species are more prone than others to cause persistent IMI are not known, but may indicate differences in virulence, adaptation to the environment of the udder, or both. Staphylococcus chromogenes seems well adapted to the udder because it has been isolated from the teat canal as well as the skin of the udder (Boddie et al., 1987; Harmon and

Table 5. Number of first-parity and older cows among healthy cows and cows with subclinical mastitis caused by IMI with Staphylococcus chromogenes, Staphylococcus epidermidis, and Staphylococcus simulans

\begin{tabular}{lrrr}
\hline & \multicolumn{2}{c}{ Lactation number } & Total \\
\cline { 2 - 4 } Category & \multicolumn{1}{c}{1} & $\geq 2$ & \\
\hline Healthy & 109 & 143 & 252 \\
S. $_{\text {. }}$ epromogenes $^{\mathrm{a}}$ & 21 & 12 & 33 \\
S. simulanidis $^{\mathrm{b}}$ & 7 & 46 & 53 \\
Total $^{\mathrm{a}}$ & 20 & 22 & 42 \\
& 157 & 223 & 380 \\
\hline
\end{tabular}

${ }^{a, b}$ Bacterial species with different superscript letters differ in distribution between lactation numbers at $P<0.001$. 
Langlois, 1989; Trinidad et al., 1990a; Matthews et al., 1992; Taponen, 2008). Taponen (2008) found isolates with matching pulsed-field gel electrophoresis (PFGE) types in samples from mastitic milk and udder skin, which supports the suggestion that $S$. chromogenes strains colonizing the skin can act as udder pathogens. In contrast, $S$. simulans is not frequently found in the teat canal or on the udder skin in cattle (Taponen, 2008). The origin of this IMI is uncertain. In a previous study in 2 herds with a high prevalence of $S$. epidermidis IMI, milk isolates were compared with isolates from the milkers' skin by using PFGE, and the same genotypic patterns were found in both groups of isolates (Thorberg et al., 2006). That study included a large number of $S$. epidermidis isolates, and a large diversity, as evaluated by PFGE, among isolates was demonstrated. The results indicate that $S$. epidermidis IMI may originate in humans.

Staphylococcus hemolyticus has been isolated from the udder skin of cows, but it is also a part of the normal skin flora of humans (Baba et al., 1980; Devriese and de Keyser, 1980), and S. xylosus is one of the staphylococcal species most commonly isolated from the normal skin flora in cattle (Kloos, 1980). Staphylococcus xylosus has also been isolated from the environment of the cow, such as in the bedding (Matos et al., 1991), and considerable diversity has been found among $S$. xylosus strains (Dordet-Frisoni et al., 2007). Staphylococcus xylosus has been considered to be nonpathogenic, but has also frequently been reported to be involved in mastitis (Harmon and Langlois, 1989; Jarp, 1991; Birgersson et al., 1992; Todhunter et al., 1993; Aarestrup and Jensen, 1997). Our unpublished data indicated that S. xylosus was often found in pure culture of milk samples from quarters both with and without an indication of mastitis, especially if milk sampling was not performed directly after milking and if samples were not chilled properly during transport to the laboratory. When testing the growth rate in milk at room temperature, S. xylosus was able to grow as fast as Escherichia coli. Moreover, on bacteriological examination of udder tissues after slaughter, a pure culture of S. xylosus was found only in the teat canal (Thorberg, B.-M., unpublished data). Thus, it is possible that the finding of pure growth of $S$. xylosus in milk samples in connection with subclinical mastitis may be an indication of teat canal colonization rather than IMI.

Most udder quarters persistently infected by $S$. chromogenes, S. epidermidis, and S. simulans had an inflammatory reaction, as measured by the CMT score, which is in line with the notion that persistent infections cause subclinical mastitis in most cases. In contrast, the novobiocin-resistant CNS species $S$. cohnii, $S$. kloosi, Staphylococcus lentus, S. saprophyticus, S. sciuri, and $S$. xylosus were the most common findings in udder quarters with a low CMT score, and few such quarters had persistent CNS IMI. Thus, these species seem to have a minor effect on udder health and could be referred to as environmental CNS. Therefore, analysis of novobiocin resistance could be used as a first simple diagnostic step to evaluate the importance of a finding of CNS.

On the cow level, the SCC did not differ between cows with subclinical $S$. chromogenes, S. epidermidis, or $S$. simulans mastitis, but all these groups had higher SCC than healthy cows. The latter finding is in line with previous studies (Birgersson et al., 1992; Todhunter et al., 1993; Taponen, 2008). Likewise, cows with persistent and nonpersistent CNS infections did not differ in CSCC. In a study on the quarter level, Taponen et al. (2007) found that the SCC varied considerably in quarters with both persistent and nonpersistent CNS IMI.

Cows with nonpersistent subclinical CNS mastitis in the present study had lower daily milk production than healthy cows and cows with persistent subclinical CNS mastitis, but production differences between CNS species were not observed within nonpersistent and persistent cow groups. The lowest milk production was found in cows with subclinical mastitis caused by nonpersistent $S$. simulans. The reasons underlying the observed findings are not clear. Possible explanations could be that high-yielding cows are more prone to persistent IMI, or that cows categorized as nonpersistently infected had been infected for some time before the first sampling, resulting in a reduction of milk production. In the latter group, a negative bacteriological sample at the second sampling indicated that the infection had been cleared from the udder, but some samples could also have been falsely negative. In support of the first hypotheses, Gröhn et al. (2004) found that cows with clinical CNS mastitis were higher milk producers than healthy control cows before the onset of mastitis.

In the present study, S. chromogenes was more often diagnosed in first-parity cows than in older cows, whereas S. epidermidis was found mainly in older cows. In line with our findings, Matthews et al. (1992) found that the prevalence of $S$. chromogenes was approximately twice as high in primiparous cows as in multiparous cows postpartum. Similar results, although using different cow materials and sampling strategies, have also been found in other studies (Harmon and Langlois, 1989; Todhunter et al., 1993; Aarestrup et al., 1995; Taponen et al., 2006). Studies on associations between $S$. epidermidis and lactation number are, however, not available. It may be hypothesized that at least some S. epidermidis strains are more contagious; that is, the longer the time in the herd, the higher the risk 
for IMI. Differences in the immune system have also been found between primiparous and multiparous cows (Mehrzad et al., 2002), which could be of importance for their susceptibility and response to IMI. Preliminary results indicate that the inflammatory response to S. epidermidis IMI may differ from that of other CNS infections because udder tissue infiltration of eosinophilic granulocytes, rather than neutrophilic granulocytes, was observed in connection with $S$. epidermidis IMI (unpublished results). Trinidad et al. (1990b) also observed tissue infiltration of eosinophils in connection with some CNS IMI. In that study, CNS were not identified to the species level.

\section{CONCLUSIONS}

Persistent IMI were the most common in quarters infected with $S$. chromogenes, S. epidermidis, and $S$. simulans, indicating that those CNS species are of more relevance for bovine subclinical mastitis than are other species. In cows with subclinical mastitis, S. epidermidis IMI were mainly found in multiparous cows and $S$. chromogenes IMI were mainly found in primiparous cows. The results did not indicate that the CNS species differed in their association with milk production, CSCC, and month of lactation in cows with subclinical mastitis.

\section{ACKNOWLEDGMENTS}

The study was financially supported by the Swedish Farmer's Foundation for Agricultural Research (Stockholm, Sweden). The authors thank Eva Olsson Engvall and Boel Harbom (National Veterinary Institute, Uppsala, Sweden) for helpful comments and assistance.

\section{REFERENCES}

Aarestrup, F. M., and N. E. Jensen. 1997. Prevalence and duration of intramammary infection in Danish heifers during the peripartum period. J. Dairy Sci. 80:307-312.

Aarestrup, F. M., H. D. Larsen, and N. E. Jensen. 1999. Characterisation of Staphylococcus simulans strains from cases of bovine mastitis. Vet. Microbiol. 66:165-170.

Aarestrup, F. M., H. C. Wegener, T. Rosdahl, and N. E. Jensen. 1995. Staphylococcal and other bacterial species associated with intramammary infections in Danish dairy herds. Acta Vet. Scand. $36: 475-487$.

Baba, E., T. Fukata, and H. Matsumoto. 1980. Ecological studies on coagulase-negative staphylococci in and around bovine udder. Pages 69-75 in Univ. Osaka Prefecture Bull. B 32. University of Osaka Prefecture, Osaka, Japan.

Birgersson, A., P. Jonsson, and O. Holmberg. 1992. Species identification and some characteristics of coagulase-negative staphylococci isolated from bovine udders. Vet. Microbiol. 31:181-189.

Boddie, R. L., S. C. Nickerson, W. E. Owens, and J. L. Watts. 1987. Udder microflora in nonlactating heifers. Agric. Pract. 8:22-25.

Davidson, T. J., I. R. Dohoo, A. W. Donald, H. Hariharan, and K. Collins. 1992. A cohort study of coagulase negative staphylococcal mastitis in selected dairy herds in Prince Edward Island. Can. J. Vet. Res. 56:275-280

Devriese, L. A., and H. de Keyser. 1980. Prevalence of different species of coagulase-negative staphylococci on teats and in milk samples from dairy cows. J. Dairy Res. 47:155-158.

Devriese, L. A., K. H. Schleifer, and G. O. Adegoke. 1985. Identification of coagulase-negative staphylococci from farm animals. J. Appl. Bacteriol. 58:45-55.

Djabri, B., N. Bareille, F. Beaudeau, and H. Seegers. 2002. Quarter milk somatic cell count in infected dairy cows: A meta-analysis. Vet. Res. 33:335-357.

Dordet-Frisoni, E., G. Dorchies, C. De Araujo, R. Talon, and S. Leroy. 2007. Genomic diversity in Staphylococcus xylosus. Appl. Environ. Microbiol. 73:7199-7209.

Eberhart, R. J, L. J. Hutchinson, and S. B. Spencer. 1982. Relationships of bulk somatic cell counts to prevalence of intramammary infections and to indices of herd production. J. Food Prot. 45:1125-1128.

Gröhn, Y. T., D. J. Wilson, R. N. Gonzalez, J. A. Hertl, H. Schulte, G. Bennett, and Y. H. Schukken. 2004. Effect of pathogenspecific clinical mastitis on milk yield in dairy cows. J. Dairy Sci. $87: 1619-1628$.

Harmon, R. J., and B. E. Langlois. 1989. Mastitis due to coagulasenegative Staphylococcus species. Agri-Practice 10:29-32.

Jarp, J. 1991. Classification of coagulase-negative staphylococci isolated from bovine clinical and subclinical mastitis. Vet. Microbiol. 27:151-158.

Klastrup, O., and P. Schmidt Madsen. 1974. Nordiske rekommendationer vedrørende mastitisundersøgelser af kirtelprover. Nord. Vet. Med. $26: 197-204$.

Kloos, W. E. 1980. Natural populations of the genus Staphylococcus. Annu. Rev. Microbiol. 34:559-592.

Kloos, W. E., and J. H. Jorgensen. 1985. Staphylococci. Pages 143-153 in Manual of Clinical Microbiology. 4th ed. E. H. Lenette, ed. Am. Soc. Microbiol., Washington, DC.

Matos, J. S., D. G. White, R. J. Harmon, and B. E. Langlois. 1991. Isolation of Staphylococcus aureus from sites other than the lactating mammary gland. J. Dairy Sci. 74:1544-1549.

Matthews, K. R., R. J. Harmon, and B. E. Langlois. 1991. Effect of naturally occurring coagulase-negative staphylococci infections on new infections by mastitis pathogens in the bovine. J. Dairy Sci. 74:1855-1859.

Matthews, K. R., R. J. Harmon, and B. E. Langlois. 1992. Prevalence of Staphylococcus species during the periparturient period in primiparous and multiparous cows. J. Dairy Sci. 75:1835-1839.

Mehrzad, J., L. Duchateau, S. Pyörälä, and C. Burvenich. 2002. Blood and milk neutrophil chemiluminescence and viability in primiparous and pluriparous dairy cows during late pregnancy, around parturition and early lactation. J. Dairy Sci. 85:32683276 .

Oliver, S. P., and B. M. Jayarao. 1997. Coagulase-negative staphylococcal intramammary infections in cows and heifers during the nonlactating and periparturient periods. Zentralbl. Veterinarmed. B 44:355-363.

Olsson, S.-O., P. Baekbo, S. Ö. Hansson, H. Rautala, and O. Østerås. 2001. Disease recording systems and herd health schemes for production diseases. Acta Vet. Scand. 94(Suppl.):51-60.

Rainard, P., and B. Poutrel. 1982. Dynamics of nonclinical bovine intramammary infections with major and minor pathogens. Am. J. Vet. Res. 43:2143-2146.

Schukken, Y. H., R. N. Gonzalez, L. L. Tikofsky, H. F. Schulte, C. G. Santisteban, F. L. Welcome, G. J. Bennett, M. J. Zurakowski, and R. N. Zadoks. 2009. CNS mastitis: Nothing to worry about? Vet. Microbiol. 134:9-14.

Swedish Dairy Association. 2007. Djurhälsovård 2006/2007. Annual Report. Swed. Dairy Assoc., Stockholm, Sweden.

Taponen, S. 2008. Bovine mastitis caused by coagulase-negative staphylocci. PhD Thesis. University of Helsinki, Helsinki, Finland.

Taponen, S., J. Koort, J. Björkroth, H. Saloniemi, and S. Pyörälä. 2007. Bovine intramammary infections caused by coagulasenegative staphylococci may persist throughout lactation according 
to amplified fragment length polymorphism-based analysis. J. Dairy Sci. 90:3301-3307.

Taponen, S., H. Simojoki, M. Haveri, H. D. Larsen, and S. Pyörälä. 2006. Clinical characteristics and persistence of bovine mastitis caused by different species of coagulase-negative staphylococci identified with API or AFLP. Vet. Microbiol. 115:199-207.

Thorberg, B.-M., and B. Brändström. 2000. Evaluation of two commercial systems and a new identification scheme based on solid substrates for identifying coagulase-negative staphylococci from bovine mastitis. J. Vet. Med. B, Infect. Dis. Vet. Public Health 47:683-691.

Thorberg, B.-M., I. Kühn, F. M. Aarestrup, B. Brändström, P. Jonsson, and M.-L. Danielsson-Tham. 2006. Pheno- and genotyping of Staphylococcus epidermidis isolated from bovine milk and human skin. Vet. Microbiol. 115:163-172.

Timms, L. L., and L. H. Schultz. 1987. Dynamics and significance of coagulase-negative staphylococcal intramammary infections. J. Dairy Sci. 70:2648-2657.
Todhunter, D. A., L. L. Cantwell, K. L. Smith, K. H. Hoblet, and J. S. Hogan. 1993. Characteristics of coagulase-negative staphylococci isolated from bovine intramammary infections. Vet. Microbiol. 34:373-380.

Trinidad, P., S. C. Nickerson, and R. W. Adkinson. 1990b. Histopathology of staphylococcal mastitis in unbred dairy heifers. J. Dairy Sci. 73:639-647.

Trinidad, P., S. C. Nickerson, and T. K. Alley. 1990a. Prevalence of intramammary infection and teat canal colonization in unbred and primigravid dairy heifers. J. Dairy Sci. 73:107-114.

Wilson, D. J., R. N. Gonzalez, and H. H. Das. 1997. Bovine mastitis pathogens in New York and Pennsylvania: Prevalence and effects on somatic cell count and milk production. J. Dairy Sci. 80:25922598 . 